\title{
Gonadectomy and high dietary fat but not high dietary carbohydrate induce gains in body weight and fat of domestic cats
}

\author{
Robert C. Backus ${ }^{1 *}$, Nick J. Cave ${ }^{2}$ and Duane H. Keisler ${ }^{3}$ \\ ${ }^{1}$ Department of Veterinary Medicine and Surgery, College of Veterinary Medicine, University of Missouri-Columbia, MO, USA \\ ${ }^{2}$ Institute of Veterinary, Animal and Biomedical Sciences, Massey University, Palmerston North, New Zealand \\ ${ }^{3}$ Divison of Animal Sciences, University of Missouri-Columbia, MO, USA
}

(Received 20 November 2006 - Revised 17 February 2007 - Accepted 1 March 2007)

\begin{abstract}
A high concentration of dietary carbohydrate is suggested to increase the risk of obesity and diabetes mellitus in domestic cats. To evaluate this, food intake, body weight, fat mass and circulating adiposity-related factors were determined in twenty-four sexually mature (9-12 months) cats assigned to four six-cat dietary groups balanced for body weight and sex. The effect of dietary fat in exchange for carbohydrate at $9,25,44$ and $64 \%$ of metabolisable energy (ME) in a purified diet of constant protein:ME ratio was studied 13 weeks before and 17 weeks after gonadectomy (GX). Body weight did not significantly change among the cats before GX except for an increase of 17 (SEM 5) \% in cats given the highest-fat diet. Following GX, all groups gained body weight, and body fat mass was positively correlated $(r 0.50 ; P<0 \cdot 04)$ with dietary fat percentage. Post-GX weight gains were much greater for females (+39 (SEM 5) \%) than males (+10 (SEM 4) \%). Plasma ghrelin concentration negatively correlated $(P<0.02)$ with dietary fat percentage and, before GX, was greater $(P<0.05)$ in females than males. Plasma insulin concentration increased with weight gain induced by high dietary fat. Plasma glucose, TAG and leptin concentrations were not affected by dietary fat percentage, GX or weight gain. These data provide evidence that in cats, high dietary fat, but not carbohydrate, induces weight gain and a congruent increase in insulin, while GX increases sensitivity to weight gain induced by dietary fat.
\end{abstract}

Obesity: Dietary fat: Neutering: Ghrelin: Cats

An evaluation of the nutrient requirements of domestic cats has led to the conclusion that cats are metabolically attuned to carnivorous diets ${ }^{1}$. As such, cats serve as useful models for studies of comparative nutrition and metabolism. Recent epidemiological investigations have yielded evidence which attributes an increased risk for obesity in cats to commercially available, high-carbohydrate, dry-expanded diets as opposed to commercially available, canned, high-fat diets ${ }^{2}$. These observations in cats deviate from experimental finding in the rodent literature, where diets high in fat are found to cause weight gain and induce obesity ${ }^{3,4}$. Mechanisms by which high-carbohydrate diets might cause obesity in cats are speculative. A high constitutive rate of glucose production from amino acid catabolism and a low capacity for glucose disposal are suggested to direct unutilised carbohydrate toward fatty acid synthesis and storage ${ }^{5}$. An alternative mechanism is that high dietary carbohydrate exposure extraordinarily prolongs insulin release, resulting in diversion of dietary fat away from oxidation toward storage in adipose. This latter mechanism seems more plausible than the former because feline liver and adipose tissues appear to poorly utilise glucose for fatty acid synthesis ${ }^{6}$.

Ingredients, energy density and palatability of high-carbohydrate, commercial dry-expanded diets are substantively different from those in most commercial canned diets. Because of this, factors other than carbohydrate content might account for an increased obesity risk when dryexpanded diets are fed. Recently, the effect of two concentrations of dietary fat (11 and $21 \%$; w/w) on body fat mass were evaluated in young cats given commercial dry-type diets soon after gonadectomy (GX; orchiectomy and ovariohysterectomy) ${ }^{7}$. Expansion of fat mass occurred with the use of both diets, but the effects on fat mass were greatest with the higher-fat diet. The observations were consistent with obesity risk being less when 'grocery-store', dry-expanded diets were used in place of higher-fat, specialty and therapeutic diets ${ }^{2}$. However, findings of other research indicate no significant effect of dietary fat content on body weight when dry-type ${ }^{8}$ or canned ${ }^{9}$ diets are used. Cats evaluated in the negative-finding studies were adults (2-4 years of age) and in some cases had gonadectomies long before dietary-fat effects were evaluated.

An understanding of the relationship between diet composition and obesity risk is necessary for healthful management of cats. Over 37 million US households are reported to own cats $^{10}$. A prevalent healthcare issue among privately owned cats $(25-40 \%)$ is overweight to obese body conditions ${ }^{2,11}$. The overweight to obese cat is at greater risk for lameness,

Abbreviations: GX, gonadectomy; ME, metabolisable energy.

* Corresponding author: Dr Robert Backus, fax +1 573884 5444, email backusr@missouri.edu 
oral disease, dermatopathy, urinary tract disease, neoplasia and diabetes mellitus ${ }^{11,12}$.

In the present study, body condition and endocrine and biochemical factors reputed to affect or associate with body condition were determined in male and female cats fed diets differing in carbohydrate concentration by isoenergetic substitution with dietary fat. Because privately owned cats are commonly gonadectomised and maintained on commercial dry-type diets in the USA, a study objective was evaluation of whether manipulation of dietary carbohydrate content might serve as an effective means of reducing weight gain induced by GX.

\section{Materials and methods}

Animals

Twelve male and twelve female purebred domestic shorthair cats, between 4 and 7 months of age, of the specific pathogen-free colony of the Feline Nutrition and Pet Care Center (University of California, Davis, CA, USA) were used. Throughout the study, diet and water were made continuously available, body weights were determined every 7 to $14 \mathrm{~d}$, temperature was maintained between 17 and $26^{\circ} \mathrm{C}$, and light and dark periods were 14 and $10 \mathrm{~h}$, respectively. Before the study, the cats were housed in group cages and provided ad libitum access to a nutritionally complete and balanced commercial extruded dry-type diet formulated for growth ${ }^{13}$. Husbandry and the experimental protocols were reviewed and approved by the University Animal Use and Administrative Advisory Committee. The cats were maintained in accordance with the NRC Guide for the Care and Use of Laboratory Animals ${ }^{14}$.

\section{Experimental protocol}

Cats were individually housed and fed for 3 months a purified adaptation diet that was nutritionally complete and balanced for growth ${ }^{15}$. Subsequently, cats were evaluated for food intake determinations for 2 months, and then the cats were assigned to four groups of six cats until the end of the study. Each group was balanced for body weight and sex and received a unique purified diet that differed in fat and carbohydrate proportion from the adaptation diet. At 3 months after the dietary group assignments, males were orchiectomised and females were ovariohysterectomised by standard techniques ${ }^{16,17}$. Jugular venous blood $(3 \mathrm{ml})$ was collected by venepuncture for plasma biochemical analyses 2 weeks before, and every 2 weeks thereafter until 9 weeks after GX. Diet was not withheld before the blood collections. Blood samples were transferred to glass tubes containing $5.5 \mathrm{mg} \mathrm{K}{ }_{3}$ EDTA (BD Vacutainer, Franklin Lakes, NJ, USA) and briefly (about $30 \mathrm{~min}$ ) stored in ice before being centrifuged (about $1200 \mathrm{~g} ; 10 \mathrm{~min}$ ) for plasma extraction. Plasma was stored at $-80^{\circ} \mathrm{C}$ until later biochemical analyses. At 17 weeks after GX, body fat and lean masses were determined by a previously validated isotopic water-dilution technique ${ }^{18}$. For this, jugular venous blood $(6 \mathrm{ml})$ was collected by venepuncture $2-3 \mathrm{~h}$ after subcutaneous administration of salinated (9 g sodium chloride/l) ${ }^{2} \mathrm{H}$-labelled water (99\%; Isotec, Inc., Miamisburg, OH, USA). One male died unexpectedly during the adaptation period without premonitory signs of illness (for example, changed activity, decreased food intake, weight loss). Necropsy findings were consistent with acute ventilatory arrest possibly caused by an idiopathic asthmatic episode $^{19}$.

\section{Diets}

The adaptation and study diets contained similar purified ingredients (Table 1). The principal carbohydrate sources were maize starch and sugar, while the fat sources were chicken fat, maize oil and hydrogenated beef tallow. The sugar:starch weight ratio was the same among the diets, except where sugar was limited to $20 \%$ of DM to minimise metabolisable energy (ME) loss from fructosuria ${ }^{20}$. Maize oil and single-cell oil (ARASCO; Martek Bioscience Corp., Columbia, MD, USA) were added to the lowest-fat diet (diet 2) to meet linoleic and arachidonic acid requirements, respectively ${ }^{15}$. These oils were added to the other diets so that all study diets contained similar weight proportions of the oils. Protein:ME ratios among the study diets were similar (Table 2). The ME distributions in fat and carbohydrate in the study diets were selected to approximate distributions typically observed in feline commercial canned diets (diet 1) and dry-type diets that are low (diets 3 ) to moderate (diet 4) in fat. Warm water was variably added to the diets for the purpose of producing similar textured pellets following extrusion of the diets through a meat-grinder die. Water was not added to the lowest-carbohydrate diet (diet 1) because the fat content of the diet was sufficient for forming soft pellets. To firm pellets of diet 1, hydrogenated beef tallow was added 1:5(w/w) with the chicken fat. So that the other diets would be of similar fat composition, the same beef tallow:chicken ratio was used.

\section{Food intake determination}

Daily DM food intakes were determined until 12 weeks postGX, when mean body weights of groups plateaued. The intakes were determined by multiplying weight of diet consumed by mean fractional DM content of respective diets. Fractional DM of diets was determined from samples collected for 5 weeks before and 5 weeks after introduction of the study diets. Fractional DM for the adaptation and study diets 1, 2, 3 and 4 were 72 (SD 6), 96 (SD 5), 72 (SD 5), 70 (SD 4) and 74 (SD 3) \%, respectively.

\section{Biochemical analyses}

Plasma and serum insulin and ghrelin concentrations were assayed in duplicate $50 \mu \mathrm{l}$ samples using commercial RIA kits (PI-12K and GHRT-89HK, respectively; Linco Research, Inc., St Joseph, MO, USA). Plasma and serum leptin concentrations were determined in duplicate $200 \mu$ l samples with a RIA based on polyclonal antiserum with multi-species leptin cross-reactivity $^{21}$. Each RIA was validated from parallelism responses to increasing dilutions of plasma from three or more cats. Glucose and TAG concentrations in plasma and serum were determined with an automated chemistry analyser (AU440e; Olympus America, Inc., Melville, NY, USA) by the Veterinary Diagnostic Laboratory, College of Veterinary Medicine, University of Missouri, Columbia, MO, USA. 
Table 1. Ingredient composition of adaptation and study diets

\begin{tabular}{|c|c|c|c|c|c|}
\hline \multirow[b]{2}{*}{ Ingredient (g/kg) } & \multicolumn{5}{|c|}{ Diet } \\
\hline & Adaptation & 1 & 2 & 3 & 4 \\
\hline Lactic casein & 200 & 234 & 163 & 179 & 203 \\
\hline $\begin{array}{l}\text { Soya protein } \\
\text { isolate }\end{array}$ & 200 & 234 & 163 & 179 & 203 \\
\hline Methionine & 4 & 3.9 & $2 \cdot 7$ & $3 \cdot 0$ & 3.4 \\
\hline Taurine & 1.5 & 1.5 & 1.5 & 1.5 & 1.5 \\
\hline Maize starch & 205 & 26 & 366 & 291 & 177 \\
\hline Sucrose & 200 & 14 & 198 & 157 & 96 \\
\hline Chicken fat & 60 & 323 & 24 & 90 & 190 \\
\hline Maize oil & 60 & 14 & 10 & 11 & 12 \\
\hline $\begin{array}{l}\text { Hydrogenated } \\
\text { tallow }\end{array}$ & - & 60 & 4 & 17 & 35 \\
\hline Single-cell oil ${ }^{*}$ & - & $2 \cdot 9$ & $2 \cdot 0$ & $2 \cdot 2$ & 2.5 \\
\hline d- $\alpha$-Tocopherol & - & 0.3 & - & 0.04 & 0.1 \\
\hline Mineral mixture $\dagger$ & 50 & 65 & 46 & 50 & 57 \\
\hline Vitamin mixture & 5 & 6.5 & 4.6 & $5 \cdot 0$ & $5 \cdot 7$ \\
\hline Choline chloride & 4.5 & 5.9 & $4 \cdot 1$ & 4.5 & $5 \cdot 1$ \\
\hline Sodium propionate & 10 & 10 & 10 & 10 & 10 \\
\hline Water & 667 & - & 667 & 667 & 428 \\
\hline
\end{tabular}

*ARASCO, 33-44\% arachidonic acid (Martek Biosciences, Columbia, MD, USA). †Composition was (g/kg mixture): $\mathrm{CaHPO}_{4}, 390 ; \mathrm{KCl}, 200 ; \mathrm{NaHCO}_{3}, 140 ; \mathrm{NaCl}$, 122; $\mathrm{CaCO}_{3}, 110 ; \mathrm{KHCO}_{3}, 100 ; \mathrm{K}_{2} \mathrm{HPO}_{4}, 90 ; \mathrm{MgSO}_{4}, 45 \cdot 0$; ferric-citrate-3 $\mathrm{H}_{2} \mathrm{O}$, $250 \mathrm{mg} ; \mathrm{ZnSO}_{4} \cdot 7 \mathrm{H} 2 \mathrm{O}, 111 \mathrm{mg} ; \mathrm{MnSO}_{4} \cdot \mathrm{H}_{2} \mathrm{O}, 96 \mathrm{mg} ; \mathrm{CuSO}_{4} \cdot 5 \mathrm{H}_{2} \mathrm{O}, 20 \mathrm{mg}$ $\mathrm{NiCl}_{2} \cdot 6 \mathrm{H}_{2} \mathrm{O}, 7.5 \mathrm{mg} ; \mathrm{CrCl} \cdot 6 \mathrm{H}_{2} \mathrm{O}, 6.5 \mathrm{mg} ; \mathrm{SnCl}_{2} \cdot 2 \mathrm{H}_{2} \mathrm{O}, 2.5 \mathrm{mg} ;\left(\mathrm{NH}_{4}\right)_{6} \mathrm{Mo}_{7} \mathrm{O}_{4} \cdot 4 \mathrm{H}_{2}$. $\mathrm{O}, 1.0 \mathrm{mg} ; \mathrm{KI}, 0.75 \mathrm{mg} ; \mathrm{Na}_{2} \mathrm{SeO}_{3}, 0.75 \mathrm{mg} ; \mathrm{NH}_{4} \mathrm{VO}_{3} \cdot 4 \mathrm{H}_{2} \mathrm{O}, 0.5 \mathrm{mg}^{50}$.

‡Composition was (g/kg mixture): sucrose, 84.3; ascorbic acid, 20; myo-inositol, 20; dl- $\alpha$-tocopheryl acetate, 16; nicotinic acid, 10; thiamin. $\mathrm{HCl}, 2 \cdot 5$; calcium pantothenate, 2.0; menadione, 1.5; retinyl palmitate, 1.1; riboflavin, 1.0; pyridoxine, 1.0 ; folic acid, 1.0; biotin, 0.1 ; cholecalciferol, $5.0 \mathrm{mg}$; cobalamin, $5.0 \mathrm{mg}^{50}$.

Because of cost constraints, analysis of ghrelin was limited to samples collected 2 weeks before and 1, 3, 5, 7, 9 and 17 weeks after GX.

\section{Statistical analysis}

The effects of dietary group assignment (diet 1 , diet 2, diet 3, diet 4) and sex (male, female) on variable observations were evaluated for each of three experimental periods - the

Table 2. Calculated weight and metabolisable energy (ME) density and percentage distribution of carbohydrate, fat and protein in purified diets ${ }^{*}$

\begin{tabular}{|c|c|c|c|c|c|}
\hline & \multicolumn{5}{|c|}{ Diet } \\
\hline & Adaptation & 1 & 2 & 3 & 4 \\
\hline \multicolumn{6}{|l|}{ DM (w/w \%) } \\
\hline Carbohydrate & 40.5 & 4.0 & $56 \cdot 4$ & $44 \cdot 8$ & $27 \cdot 3$ \\
\hline Fat & $12 \cdot 0$ & $40 \cdot 0$ & $4 \cdot 0$ & $12 \cdot 0$ & $24 \cdot 0$ \\
\hline Protein & $40 \cdot 0$ & $46 \cdot 8$ & $32 \cdot 7$ & $35 \cdot 8$ & $40 \cdot 5$ \\
\hline \multicolumn{6}{|l|}{ ME (kJ/kJ \%)† } \\
\hline Carbohydrate & $37 \cdot 7$ & $2 \cdot 8$ & $57 \cdot 0$ & 41.3 & $22 \cdot 2$ \\
\hline Fat & $25 \cdot 1$ & $63 \cdot 5$ & $9 \cdot 1$ & $24 \cdot 9$ & $44 \cdot 0$ \\
\hline Protein & $37 \cdot 7$ & 33.0 & 33.0 & 33.0 & $33 \cdot 0$ \\
\hline \multicolumn{6}{|l|}{ ME density $(\mathrm{kJ} / \mathrm{g}) \ddagger$} \\
\hline DM basis & $18 \cdot 0$ & $23 \cdot 8$ & $16 \cdot 7$ & $18 \cdot 0$ & $20 \cdot 5$ \\
\hline As-presented basis & $13 \cdot 0$ & $23 \cdot 0$ & $12 \cdot 1$ & $12 \cdot 5$ & 15.5 \\
\hline
\end{tabular}

* Maize starch and sugar, casein and soya protein, and chicken fat, tallow and vegetable oils were considered dietary carbohydrate, protein and fat sources, respectively.

† It was assumed that protein, fat and carbohydrate contained 17, 38 and $17 \mathrm{~kJ} / \mathrm{g}$, respectively ${ }^{22}$.

$\ddagger$ Calculated using the arithmetic mean of fresh diet moisture content and moisture content in diet remaining in food bowls at the time of replacement with fresh diet. adaptation (pre-GX, common diet), diet-change (pre-GX, group-defining diets) and post-GX (group-defining diets) periods. The variables studied were food intake and body weight for all periods, plasma concentrations of insulin, leptin, ghrelin, glucose and TAG for the diet-change and post-GX periods, and body lean and fat masses for the postGX period. General linear models ANOVA and post hoc least-squares difference analysis were used to determine the significance of variable differences with diet and sex. A repeated-measures ANOVA model was used when observations on variables were repeated three or more times. Percentage change data were logarithmic transformed before analyses. Paired $t$ tests were used to evaluate effects among variables when only two observations were considered. Regression analysis was used for evaluation of effect of concentration of dietary fat on body lean mass, body fat mass, percentage body fat and percentage change in body weight. Computer software used for the analyses was SAS 9.1 (SAS Institute Inc., Cary, NC, USA). Unless specified, variance estimates are reported as mean values with their standard errors. Differences with $P \leq 0.05$ were considered significant; those with $P>0.05<0.10$ were considered a trend.

\section{Results}

\section{Food intake}

Food intake was evaluated as intake of ME, because the study diets varied in moisture content and energy density. Intakes of ME were calculated as the product of DM intake and DM ME density as estimated from the Atwater values of 17, 38 and $17 \mathrm{~kJ} / \mathrm{g}$ for dietary protein, fat and carbohydrate, respectively $^{22}$. Because within-animal variation in food intake was typically large between days, $7 \mathrm{~d}$ mean ME intakes were determined for each cat and used in analyses of effects of diet, sex and GX. Throughout the study, ME intakes by the males were greater $(P<0 \cdot 05)$ than those by the females. During the adaptation period, no group differences $(P>0.05)$ were observed in ME intakes (Table 3).

Within-group variance in ME intake was large for both sexes (Table 3). Among dietary groups, maximum intakes were between 150 and $270 \%$ of minimum intakes. Because of this, treatment effects on food intake were evaluated against percentage change in ME intake. ME intakes observed in cats assigned to each group during the last week of the adaptation period were used as reference intakes for calculating percentage change in ME intake caused by introduction of the study diets; diets 1, 2, 3 and 4 . When the study diets were introduced (Fig. 1; weeks 1 to 13), ME intake changed with time $(P<0.01)$ and significant time $\times \operatorname{diet}(P<0.02)$ and time $\times$ sex interactions $(P<0 \cdot 01)$ were observed (Table 4$)$. During weeks $1,2,3$ and 6 , percentage change in $\mathrm{ME}$ intake by females given the highest-fat diet $(64 \% \mathrm{ME})$ was greater $(P<0.05)$ than that by females given the other study diets. In males, percentage change in ME intake was greater $(P<0.05)$ in cats given the highest-fat diet than in cats given the lowest-fat diets ( 9 and $25 \% \mathrm{ME}$ ) during week 1. The percentage change in ME intake of the highest-fat diet was greater $(P<0.05)$ than that of the next highest-fat diet (44\% ME) during weeks 4 and 6 by the females and during week 4 by the males. An additional dietary difference was 
Table 3. Daily dietary mass and energy intakes by eleven male and twelve female cats during the last week of each experimental period for which food intakes were determined

(Mean values with their standard errors)

\begin{tabular}{|c|c|c|c|c|c|c|c|c|c|}
\hline \multirow[b]{2}{*}{ Period } & \multirow[b]{2}{*}{ Sex } & \multirow[b]{2}{*}{ Group } & \multirow[b]{2}{*}{ Diet (\% fat) } & \multicolumn{2}{|c|}{ As-fed $(g / d)$} & \multicolumn{2}{|c|}{$\mathrm{DM}(\mathrm{g} / \mathrm{d})$} & \multicolumn{2}{|c|}{ ME (MJ/d) } \\
\hline & & & & Mean & SEM & Mean & SEM & Mean & SEM \\
\hline \multirow[t]{8}{*}{ Adaptation } & \multirow[t]{4}{*}{ Male } & 1 & 25 & 116 & 12 & 84 & 9 & 1.51 & 0.16 \\
\hline & & 2 & 25 & 144 & 17 & 104 & 12 & 1.88 & 0.22 \\
\hline & & 3 & 25 & 143 & 16 & 104 & 12 & 1.87 & 0.21 \\
\hline & & 4 & 25 & 131 & 18 & 95 & 13 & $1 \cdot 70$ & 0.24 \\
\hline & \multirow[t]{4}{*}{ Female } & 1 & 25 & 100 & 6 & 72 & 5 & $1 \cdot 30$ & 0.08 \\
\hline & & 2 & 25 & 100 & 6 & 72 & 5 & $1 \cdot 30$ & 0.08 \\
\hline & & 3 & 25 & 88 & 8 & 64 & 6 & $1 \cdot 15$ & 0.11 \\
\hline & & 4 & 25 & 87 & 12 & 63 & 9 & $1 \cdot 13$ & 0.16 \\
\hline \multirow[t]{8}{*}{ Diet-change* } & \multirow[t]{4}{*}{ Male } & 1 & 9 & 104 & 23 & 74 & 17 & 1.24 & 0.28 \\
\hline & & 2 & 25 & 121 & 38 & 85 & 27 & 1.56 & 0.49 \\
\hline & & 3 & 44 & 74 & 14 & 55 & 10 & $1 \cdot 14$ & 0.22 \\
\hline & & 4 & 64 & 61 & 15 & 58 & 15 & 1.39 & 0.35 \\
\hline & \multirow[t]{4}{*}{ Female } & 1 & 9 & 90 & 14 & 64 & 10 & 1.07 & 0.17 \\
\hline & & 2 & 25 & 88 & 13 & 62 & 9 & $1 \cdot 13$ & 0.17 \\
\hline & & 3 & 44 & 52 & 10 & 38 & 7 & 0.80 & 0.15 \\
\hline & & 4 & 64 & 57 & 12 & 55 & 12 & $1 \cdot 31$ & 0.28 \\
\hline \multirow[t]{8}{*}{ Post-GX† } & \multirow[t]{4}{*}{ Male } & 1 & 9 & 189 & 28 & 136 & 20 & $2 \cdot 26$ & 0.34 \\
\hline & & 2 & 25 & 213 & 19 & 149 & 13 & $2 \cdot 73$ & 0.25 \\
\hline & & 3 & 44 & 124 & 7 & 92 & 5 & 1.91 & 0.11 \\
\hline & & 4 & 64 & 92 & 12 & 89 & 12 & $2 \cdot 10$ & 0.28 \\
\hline & \multirow[t]{4}{*}{ Female } & 1 & 9 & 160 & 33 & 115 & 24 & 1.92 & 0.40 \\
\hline & & 2 & 25 & 126 & 28 & 88 & 19 & 1.62 & 0.36 \\
\hline & & 3 & 44 & 98 & 8 & 73 & 6 & 1.50 & 0.13 \\
\hline & & 4 & 64 & 75 & 8 & 72 & 8 & 1.70 & 0.19 \\
\hline
\end{tabular}

ME, metabolisable energy; GX, gonadectomy

*Intakes during week 13 after diet change.

†Intakes during post-GX week 12.

found for females during week 6 , when the percentage change in $\mathrm{ME}$ intake of the $9 \% \mathrm{ME}$ diet was greater $(P<0.05)$ than that of the percentage change in ME intake of the $44 \%$ diet.

ME intakes during the week preceding GX (Fig. 1; week 13) were used as reference intakes for calculating percentage changes in ME intake induced by GX. During the post-GX period (weeks 14 to 26), percentage change in ME intake did not significantly vary with diet or between males and females. However, percentage change in ME intake did vary with time $(P<0 \cdot 01)$ and a time $\times$ diet interaction $(P<0 \cdot 01)$ occurred (Table 4$)$. By the last week of the postGX period, mean ME intake across the dietary groups was 163 (SEM 8) \% of reference pre-GX ME intakes.

\section{Body weight}

During the adaptation period, body weights among the cats did not vary with dietary group assignment, and the body weights of males were greater $(P<0 \cdot 01)$ than those of females. Time $(P<0 \cdot 01)$ and time $\times$ sex interaction $(P<0 \cdot 01)$ effects were observed during this period. Mean body weights of males and females increased $(P<0.02)$ by 9.6 (SEM 1.6) and 3.8 (SEM 1.4) \%, respectively. The percentage increase in males was greater $(P<0.03)$ than that in females. During the last week of the adaptation period, mean body weights of males assigned to dietary groups $1,2,3$ and 4 were 4.41 (SEM 0.46 ), 4.30 (SEM 0.55), 4.58 (SEM 0.20) and 4.53 (SEM 0.04) $\mathrm{kg}$, respectively, while those of females were 2.72 (SEM $0 \cdot 25$ ), $2 \cdot 70$ (SEM 0.21), $2 \cdot 75$ (SEM 0.17) and 2.72 (SEM 0.10) $\mathrm{kg}$, respectively. Although mean body weights among males and females of each group were similar, within-group variances were large in some of the groups; therefore, percentage change in body weight was used in the evaluation of effects of diet and GX. Reference body weights were those observed during the week immediately preceding study diet introduction and body weights observed the week before gonadectomies.

Percentage change in body weight varied $(P<0 \cdot 01)$ among the dietary groups by week 13 following introduction of the study diets (Fig. 2). Change in body weight of cats given the highest-fat diet $(64 \% \mathrm{ME}$ as fat) was greater $(P<0.05)$ than that in cats given the other diets during the last few weeks of the period. By week 13, body weights of cats given the highest-fat diet increased by a mean of 17.0 (SEM 5.0) $\%$, while for cats given the other diets, no significant change in body weight was observed. Body weights of males were consistently greater $(P<0.05)$ than those of females during this period.

During the post-GX period, no effect of diet or sex on percentage change in body weight was observed (Table 4$)$, yet time $(P<0.01)$ and time $\times \operatorname{sex}(P<0.01)$ effects were found (Fig. 2). By week 13 of the post-GX period, mean body weight of males increased by 10.4 (SEM 3.5) \% while that of females increased by 39.4 (SEM 5.1) \%. The percentage change in body weight at the end of the post-GX period, relative to the body weight at the end of the adaptation period, was determined for each cat. Regression analyses of these observations revealed that percentage change in body weight 
(A)

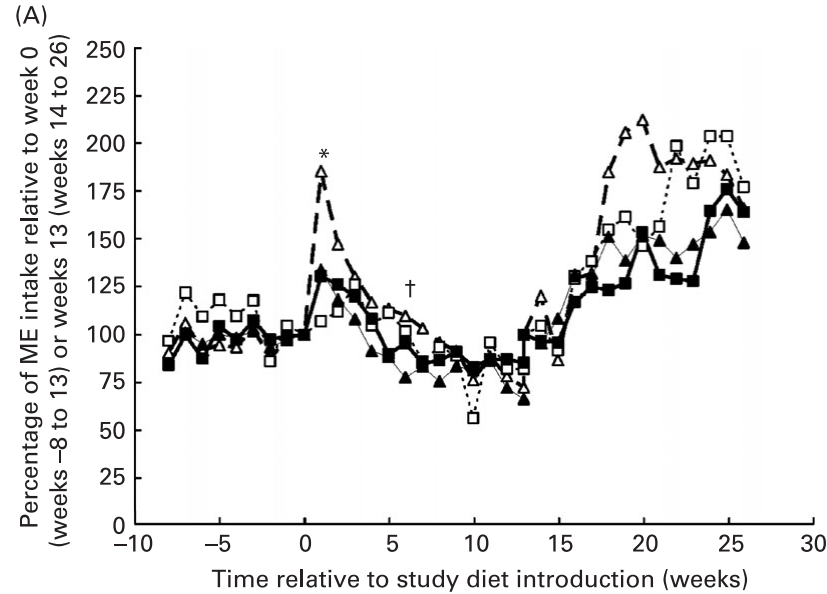

(B)

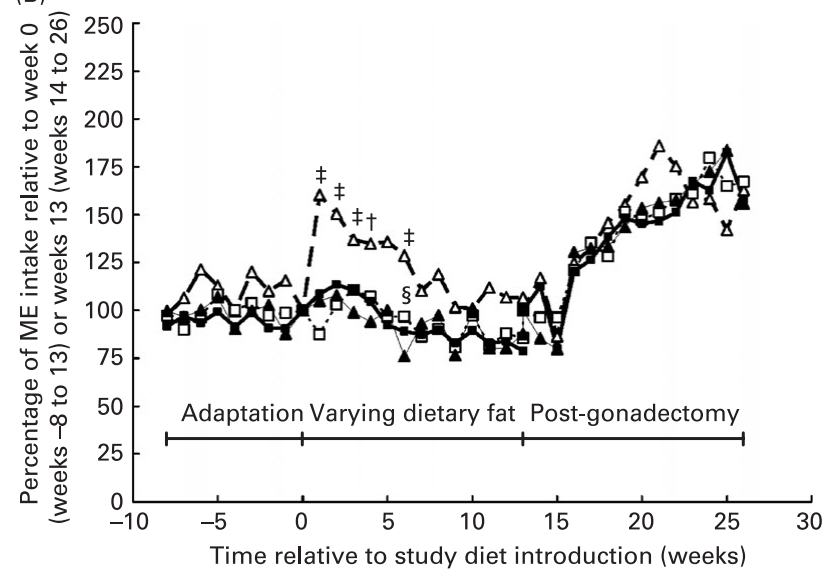

Fig. 1. Percentage changes in metabolisable energy (ME) intake by male (A) and female (B) cats adapted to the same purified diet (weeks -8 to 0 ), then given purified diets of varying fat content before (weeks 1 to 13) and after

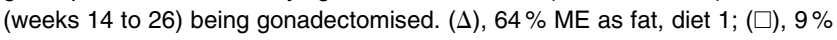

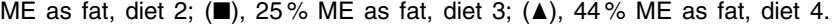
Values are means of observations for three cats (or two cats in the case of males given the $9 \% \mathrm{ME}$ as fat diet). Changes in ME intake before gonadectomy are relative to week $0 \mathrm{ME}$ intakes. Changes in ME intake following gonadectomy are relative to week $13 \mathrm{ME}$ intakes. For clarity, SEM estimates are not plotted. Means of SEM observed across groups for the adaptation, pre-gonadectomy varying dietary fat, and post-gonadectomy periods are 8.6 , 11.1 and $19.4 \%$, respectively. ${ }^{*}$ Mean value for diet 1 was significantly greater than those for diets 2 and $3(P<0.05)$. †Mean value for diet 1 was significantly greater than that for diet $4(P<0.05)$. $\ddagger$ Mean value for diet 1 was significantly greater than those for diets 2,3 and $4(P<0.05)$. §Mean value for diet 2 was significantly greater than that for diet $4(P<0.05)$.

increased with dietary fat, and that percentage change in body weight was greater at any level of dietary fat in females (weight change $=122+0.50 \quad(\%$ fat $\mathrm{ME}) \% ; r \quad 0.59$; $P<0.04)$ than males (weight change $=92+0.61 \quad(\%$ fat ME) $\% ; r 0.80 ; P<0.03)$.

\section{Body composition}

During post-GX week 17, when body compositions were determined after withholding of diet, body weights and lean masses of males were greater $(P<0.05)$ than those of females (Table 5). Body fat mass and body weight percentage as fat of
Table 4. Significance of percentage change in metabolisable energy (ME) intake and body weight of eleven male and twelve female cats during 8 weeks of adaptation to a purified diet, 13 weeks after introduction to diets varying in fat content $(9,25,44$ and $64 \% \mathrm{ME}$ as fat) and 13 weeks after gonadectomy

\begin{tabular}{llccc}
\hline & & \multicolumn{3}{c}{ Period } \\
\cline { 3 - 5 } Variable & Treatment & Adaptationt & $\begin{array}{c}\text { Diet- } \\
\text { change† }\end{array}$ & $\begin{array}{c}\text { Post- } \\
\text { gonadectomy }\end{array}$ \\
\hline ME intake & Diet & NS & NS & NS \\
& Sex & NS & NS & NS \\
& Diet $\times$ sex & NS & NS & NS \\
& Time & $<0.01$ & $<0.01$ & $<0.01$ \\
& Time $\times$ diet & NS & $<0.02$ & $<0.01$ \\
& Time $\times$ sex & NS & $<0.01$ & NS \\
& Time $\times$ sex & NS & NS & NS \\
Body weight & $\times$ diet & NS & $<0.01$ & NS \\
& Diet & $<0.01$ & NS & NS \\
& Sex & NS & NS & NS \\
& Diet $\times$ sex & $<0.01$ & $<0.01$ & $<0.01$ \\
& Time & NS & $<0.01$ & NS \\
& Time $\times$ diet & $<0.01$ & NS & $<0.01$ \\
& Time $\times$ sex & $<01$ & NS & NS \\
& Time $\times$ sex & NS & & \\
& $\times$ diet & & &
\end{tabular}

* For the adaptation period, 'Diet' represents dietary group to which the cats were later assigned.

†The reference body weights for determination of percentage change were body weights observed during the last week of the adaptation period.

$\ddagger$ The reference body weights for this period were those observed during the week immediately preceding the period.

males were not significantly different from those of females. Body fat masses of cats given the $64 \% \mathrm{ME}$ as fat diet were greater $(P<0.05)$ than those in cats given the 9 and $25 \%$ fat diets but not in cats given the $44 \%$ fat diet. Lean mass did not differ with diet. The body fat observations were pooled within treatment, across sex, and regressed against dietary energy as fat using linear and quadratic models. Body fat mass and percentage body fat increased with increasing dietary fat $(P<0.05)$. Greater correlations were found with quadratic than linear models (Fig. 3). The quadratic relationships indicated that body fat mass would have been minimised when dietary fat was $22 \%$ of ME, while percentage body fat would have been minimised when dietary fat was $19 \%$ of ME.

\section{Plasma insulin, glucose and triacylglycerol}

At 2 weeks before GX, plasma concentrations of insulin in cats given the highest-fat diet $(64 \% \mathrm{ME})$ were greater $(P<0.05)$ than those of cats given the lower-fat diets $(9,25$ and $44 \% \mathrm{ME}$ ) (Table 6). During the post-GX period, a diet effect on plasma insulin was not observed, but time $(P<0.01)$ and time $\times \operatorname{sex}(P<0.05)$ effects were observed. Plasma concentrations of insulin in females were greater $(P<0.05)$ and typically more than twice those in the males during post-GX weeks 6,7 and 8 (Fig. 4). Plasma concentrations of glucose and TAG did not differ with diet or sex before or after GX. Plasma concentrations of glucose differed with time $(P<0.01)$ following GX, but a consistent trend with time was not observed (Table 7). 

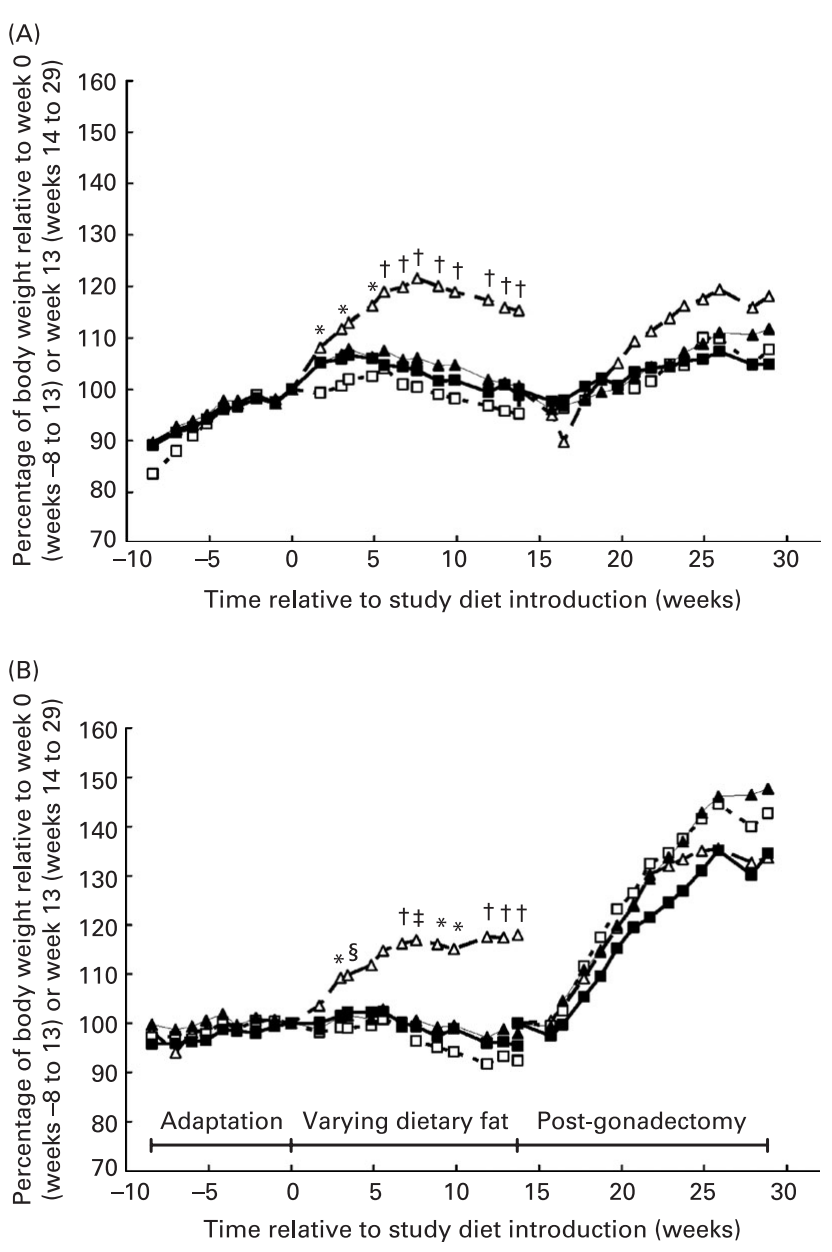

Fig. 2. Percentage changes in body weight of male $(A)$ and female $(B)$ cats adapted to the same purified diet (weeks -8 to 0 ), then given purified diets of varying fat content before (weeks 1 to 13) and after (weeks 14 to 29) being gonadectomised. $(\Delta), 64 \%$ Metabolisable energy (ME) as fat, diet $1 ;(\square), 9 \%$ ME as fat, diet 2; (ם), 25\% ME as fat, diet 3; ( $\mathbf{\Delta}), 44 \% \mathrm{ME}$ as fat, diet 4 . Values are means of observations of three cats (or two cats in the case of males given the $9 \% \mathrm{ME}$ as fat diet). Changes in body weight before gonadectomy are relative to week 0 body weights. Changes in body weight following gonadectomy are relative to week 13 body weights. For clarity, SEM estimates are not plotted. Means of SEM observed across groups for the adaptation, pre-gonadectomy varying dietary fat, and post-gonadectomy periods are $2.4,3.1$ and $5.9 \%$, respectively. *Mean value for diet 1 was significantly greater than that for diet $2(P<0.05)$. †Mean value for diet 1 was significantly greater than those for diets 2,3 and $4(P<0.05)$. ¥Mean value for diet 1 was significantly greater than those for diets 2 and $3(P<0.05)$. §Mean value for diet 1 was significantly greater than those for diets 2 and $4(P<0.05)$.

\section{Plasma leptin and ghrelin}

Plasma concentrations of leptin before and after GX did not vary with diet, sex or percentage change in body weight (Table 7). Pre-GX plasma ghrelin concentrations did not vary with dietary fat, but concentrations in females were greater $(P<0 \cdot 05)$ than those in males (Table 6). The sex difference was not found during the post-GX period. For weeks 1, 3 and 7 after GX, plasma ghrelin concentrations in cats given the highest-fat diet were significantly lower $(P<0.05)$ than those in cats given the lowest-fat diets, 25 and $9 \% \mathrm{ME}$ as fat (Fig. 5). The mean of plasma ghrelin concentrations determined for the post-GX period decreased with increasing dietary percentage $\mathrm{ME}$ as fat (ghrelin concentration $=2.4 \quad-0.017 \quad(\%$ fat $\mathrm{ME}) \quad \mathrm{ng} / \mathrm{ml} ; \quad r \quad 0.49$; $P<0.02)$. When food was withheld during week 17 of the post-GX period, plasma ghrelin concentration did not vary among dietary groups or between males and females. Plasma ghrelin concentrations tended to decrease $(P<0.06)$ as body weight increased (ghrelin concentration $=2.5-0.24$ (body weight ${ }_{\mathrm{kg}}$ ) ng/ml; $r 0 \cdot 36 ; P=0 \cdot 09$ ).

\section{Discussion}

In males and females of each dietary group, ME intake and body weight substantially increased following GX (Figs. 1 and 2). These observations are consistent with previous reports on effects of GX on cats ${ }^{7,23-28}$. An effect of carbohydrate on body weight was found, but it was opposite to that which might be inferred from epidemiological findings $^{2}$. As dietary carbohydrate concentration decreased from 44 to $9 \%$ of $\mathrm{ME}$, body weight increased. It is relevant to note that dietary carbohydrate was varied by isoenergetic substitution of fat for carbohydrate. With respect to dietary fat concentration, the present findings in cats (Fig. 3) are in agreement with previous findings in human subjects and other species; as dietary fat concentration is increased, the risk for weight gain is increased ${ }^{3,4,29}$.

Although dietary fat is reputed to enhance the palatability of diets made for cats ${ }^{30}$, simple palatability differences do not appear to account for the observed effects of dietary fat on body weight. An initial over-consumption by cats fed the highest-fat diet (64\% of ME as fat) occurred (Fig. 1), and this was associated with a substantive weight gain $(+17 \cdot 0$ (SEM 5.0) \%). While body weight of these cats increased in response (Fig. 2), food intake tended to decrease over time toward amounts observed in cats given the lower-fat diets. In contrast, changes in ME intake and body weight were similar among the other groups despite their consuming diets that ranged widely in fat content ( 9 to $44 \% \mathrm{ME}$ as fat) (Figs. 1 and 2 ). Together, these findings may indicate a threshold exists at which dietary fat content induces body-weight gain in sexually intact animals. Such a threshold might vary between individuals. For cats given the highest-fat diet, the extent of change in body weight ranged from a slight net loss in one cat $(-3 \%)$ to gains of 7 to $29 \%$ in the other five cats. The decrease in food intake in the cats fed the highest-fat diet that followed the initial increase may have been a compensatory response by controlling elements of body energy balance. If the response in food intake was compensatory, it was not completely effective. Body weights of cats given the highfat diet remained greater than those of the other cats. The high-fat diet might have evoked a resetting of the body fat mass to be defended. Such resetting as a result of high dietary fat is suggested to occur in other species ${ }^{31}$.

Gonadectomy had by far a more potent effect on ME intake and body weight than feeding of the high-fat diet. Body weight increased irrespective of dietary fat content after GX. Mean ME intakes by all dietary groups were increased by more than $25 \%$ by post-GX week 4 (Fig. 1). When bodyweight gains among the groups began to level off (Fig. 2), mean ME intakes by each dietary group were increased by more than $50 \%$ of the pre-GX intakes. These results clearly show that manipulation of dietary fat or carbohydrate content 
Table 5. Body composition 17 weeks after gonadectomy of eleven male and twelve female cats given for 32 weeks purified diets containing 9, 25, 44 and $64 \%$ metabolisable energy as fat ${ }^{\star}$

(Mean values with their standard errors)

\begin{tabular}{|c|c|c|c|c|c|c|c|c|c|c|c|}
\hline \multirow[b]{2}{*}{ Sex } & \multirow[b]{2}{*}{ Diet (\% fat) } & \multicolumn{2}{|c|}{$\begin{array}{l}\text { Body weight } \\
\qquad(\mathrm{kg}) \dagger\end{array}$} & \multicolumn{2}{|c|}{$\begin{array}{l}\text { Body weight } \\
\text { (\% change) } \ddagger\end{array}$} & \multicolumn{2}{|c|}{$\begin{array}{l}\text { Lean mass } \\
\qquad(\mathrm{kg}) \dagger\end{array}$} & \multicolumn{2}{|c|}{ Fat mass $(\mathrm{kg})$} & \multicolumn{2}{|c|}{$\begin{array}{c}\text { Fat mass } \\
(\%) \S\end{array}$} \\
\hline & & Mean & SEM & Mean & SEM & Mean & SEM & Mean & SEM & Mean & SEM \\
\hline \multirow[t]{4}{*}{ Male } & 9 & $4 \cdot 3$ & 0.3 & 7 & 6 & 3.7 & 0.4 & 0.6 & 0.7 & 13 & 15 \\
\hline & 25 & 4.7 & 0.4 & 5 & 7 & 3.7 & 0.1 & 1.1 & 0.5 & 21 & 10 \\
\hline & 44 & $5 \cdot 1$ & 0.1 & 11 & 3 & 3.5 & 0.1 & 1.5 & 0.1 & 30 & 2 \\
\hline & 64 & $6 \cdot 0$ & 0.9 & 17 & 10 & 3.6 & 0.4 & $2 \cdot 4$ & 0.5 & 40 & 3 \\
\hline \multirow{4}{*}{ Female } & 9 & 3.6 & 0.5 & 43 & 13 & 2.7 & 0.3 & 0.8 & 0.2 & 23 & 2 \\
\hline & 25 & 3.6 & 0.4 & 37 & 10 & $2 \cdot 8$ & 0.2 & 0.8 & 0.3 & 21 & 6 \\
\hline & 44 & 3.9 & 0.4 & 48 & 12 & 3.0 & 0.1 & 1.0 & 0.3 & 24 & 5 \\
\hline & 64 & 4.2 & 0.6 & 31 & 8 & 2.9 & 0.1 & 1.4 & 0.5 & 30 & 8 \\
\hline
\end{tabular}

${ }^{*}$ For details of diets 2, 3, 4 and 1, see Tables 1 and 2.

† Mean values for males were greater than those for females $(P<0.05)$.

$\ddagger$ Percentage change in body weight from the week preceding gonadectomy. Body weight increased $(P<0.05)$ in both sexes, but the increase was greater $(P<0.05)$ in females than males.

$\S$ Body fat mass expressed as a percentage of body weight.

does not prevent body-weight gain after GX when food is presented for ad libitum consumption.

An effect of dietary fat on food intake could not be identified during the post-GX period. The power for identifying a food intake effect was reduced by increased, between-individual variation in food intake. Definitive evaluation of an effect of fat following GX will require study of greater numbers of cats than presently used.

Post-GX body-weight gain percentages in females were much greater than those in males (Table 5). The sex difference is consistent with findings of some previous studies ${ }^{7,32}$ but not

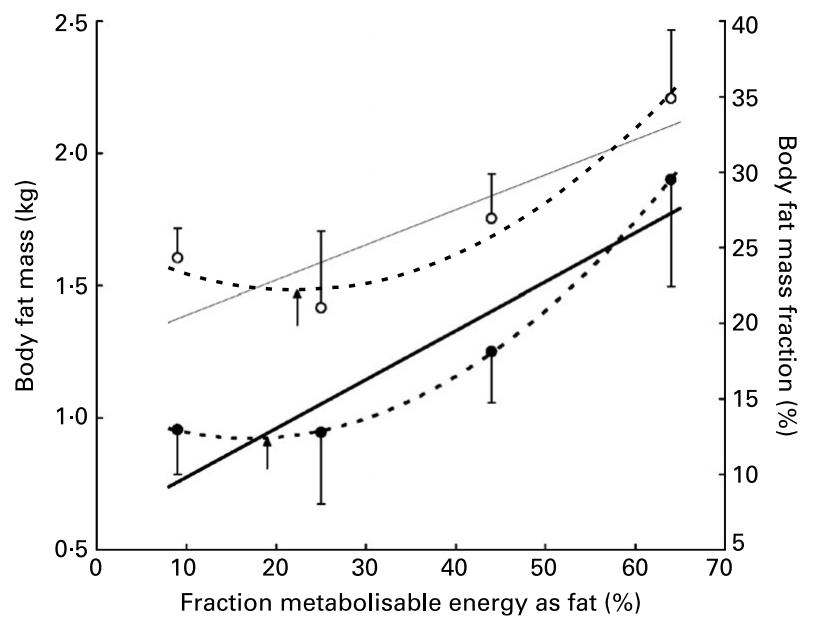

Fig. 3. Body fat mass $(\bullet)$ and body weight percentage $(O)$ as fat in cats as a function of dietary fat content as metabolisable energy (ME). The cats were given diets of varying fat content for 32 weeks and gonadectomised 17 weeks before the body-weight and fat-mass determinations. Values are means (observations for five to six cats), with their standard errors represented by vertical bars. Plotted lines are linear $(-,-)$ and quadratic (..., $--)$ regression functions derived for body fat mass (fat mass $=0.59+0.018$ ( $\%$ fat $\mathrm{ME}) \mathrm{kg} ; r 0.49 ; P<0.02$ and fat mass $=1.1-0.015(\%$ fat $\mathrm{ME})$ $\left.+0.00044(\% \text { fat ME) })^{2} ; r 0.53 ; P<0.05\right)$ and body fat percentage (fat percentage $=18+0.23(\%$ fat $\mathrm{ME}) \% ; r 0.45 ; P<0.04$ and fat percentage $=26$ $-0.33(\%$ fat $\left.\mathrm{ME})+0.0074(\% \text { fat } \mathrm{ME})^{2} ; r 0.51 ; P<0.06\right)$. $\uparrow$, Quadratic function minima. all $^{33}$. Observation of a sex difference may depend on when body weights are evaluated relative to GX. Previous comparisons of body-weight gain soon after GX, as in the present study, show greater percentage gains in females than males. Later post-GX comparisons show no significant sex difference $^{33,34}$ or increased incidence of overweight males relative to females ${ }^{2}$. Two factors might account for study variations. First, within a few weeks of GX, the RMR in females is suggested to decrease $\mathrm{e}^{24,27}$, whereas in males no such change is reported ${ }^{28}$. The sex difference may be explained by an initial post-GX weight gain in females that is greater than that in males. Second, males reportedly have lower insulin sensitivity (less by $37 \%$ ) than females, and their insulin sensitivity declines with body-weight gain ${ }^{35}$. If insulin sensitivity of adipose as opposed to other tissues is not affected during weight gain in cats, then chronically, the lower insulin sensitivity of males relative to females may be manifested as a greater shunting of dietary energy toward adipose.

Declining insulin sensitivity of adipose in man is suggested to underlie the rise in plasma TAG concentration that occurs with weight gain ${ }^{36}$. Plasma TAG concentration did not significantly change with post-GX body-weight gain in the present study (Fig. 4). A similar constancy of circulating TAG between lean and obese cats has been previously reported ${ }^{37}$. Hence, sex differences observed in post-GX weight gain of cats may reflect interactions of several factors, including sex differences in metabolic rate and insulin sensitivity and resilience in insulin sensitivity of adipose in the face of bodyweight gain.

The present (Fig. 1) and previous studies ${ }^{25,32}$ show that food intake by male and female cats is increased soon after GX. Reduction in feedback inhibition of food intake, perhaps mediated by changes in adiposity signals, is suggested to cause the rise in food intake induced by $\mathrm{GX}^{28}$. In cats that are sexually intact or that have been gonadectomised long before they are evaluated, plasma leptin concentration is found to increase with body weight and fat mass ${ }^{18,38,39}$. This finding is consistent with a suggested adipostat function for leptin in cats. However, our finding of no significant change in plasma leptin concentration within 17 weeks of GX was 
Table 6. Plasma biochemical and hormone concentrations in eleven male and twelve female, sexually intact, cats given for 12 weeks purified diets containing 9,25, 44 and $64 \%$ metabolisable energy as fat ${ }^{\star}$

(Mean values with their standard errors)

\begin{tabular}{|c|c|c|c|c|c|c|c|c|c|c|}
\hline \multirow[b]{2}{*}{ Diet (\% fat) } & \multicolumn{2}{|c|}{ Insulin $(\mu \mathrm{U} / \mathrm{ml})$} & \multicolumn{2}{|c|}{ Leptin (ng/ml) } & \multicolumn{2}{|c|}{$\begin{array}{c}\text { Ghrelin } \\
(\mathrm{ng} / \mathrm{ml}) \dagger\end{array}$} & \multicolumn{2}{|c|}{ Glucose (mM) } & \multicolumn{2}{|c|}{ TAG (mM) } \\
\hline & Mean & SEM & Mean & SEM & Mean & SEM & Mean & SEM & Mean & SEM \\
\hline 9 & $5 \cdot 8^{\mathrm{a}, \mathrm{b}}$ & 0.7 & 3.8 & 1.0 & 1.9 & 0.3 & 4.0 & 0.1 & 0.7 & 0.2 \\
\hline 25 & $4 \cdot 5^{\mathrm{a}, \mathrm{b}}$ & 1.3 & $2 \cdot 4$ & 0.5 & $2 \cdot 0$ & 0.3 & 4.2 & 0.2 & 0.6 & 0.2 \\
\hline 44 & $3 \cdot 5^{\mathrm{a}}$ & 0.5 & $2 \cdot 8$ & 0.6 & 1.5 & 0.6 & 3.9 & 0.1 & 0.8 & 0.2 \\
\hline 64 & $6 \cdot 7^{b}$ & 0.9 & $2 \cdot 3$ & 0.2 & 1.3 & 0.2 & 4.4 & 0.7 & 1.2 & 0.2 \\
\hline
\end{tabular}

a,b Mean values within a column with unlike superscript letters were significantly different $(P<0.05)$

${ }^{*}$ For details of diets 2, 3, 4 and 1 , see Tables 1 and 2.

† Mean value among males $(1.2($ SEM 0.2$) \mathrm{ng} / \mathrm{ml})$ was less $(P<0.05)$ than that among females $(2.1(\mathrm{SEM} 0.3) \mathrm{ng} / \mathrm{ml})$.

unexpected because body weight had increased by $10 \%$ in males and $39 \%$ in females. Circulating leptin has been suggested to be a more sensitive indicator of adipose energy deficit rather than abundance ${ }^{40}$. More substantive increases in body fat may have been needed to significantly raise plasma leptin. Martin et al. ${ }^{41}$ and Kanchuk et $a l .{ }^{28}$ report significant rises in plasma leptin of GX cats only after 10 to 16 weeks. GX may cause changes in leptin secretion to lag behind gains in adipose mass. The present leptin observations may have been made during a period of post-GX insensitivity in leptin response to expanding adipose mass.

Like leptin, insulin is an evinced adipostat ${ }^{42}$ and its plasma concentration in cats is increased with increasing body weight and fat mass ${ }^{43}$. Plasma insulin concentration increased in gonadectomised females of the present study as they gained body weight (Fig. 4). A similar trend was not observed among the males, but their post-GX body-weight gains (10 (SEM 4) \%) were considerably less than those in the females (39 (SEM 5) \%). Plasma insulin concentrations in males and females given the highest-fat diet were greater than the concentrations in males and females given the lower-fat diets (Table 5). Because cats given the highest-fat diet had the

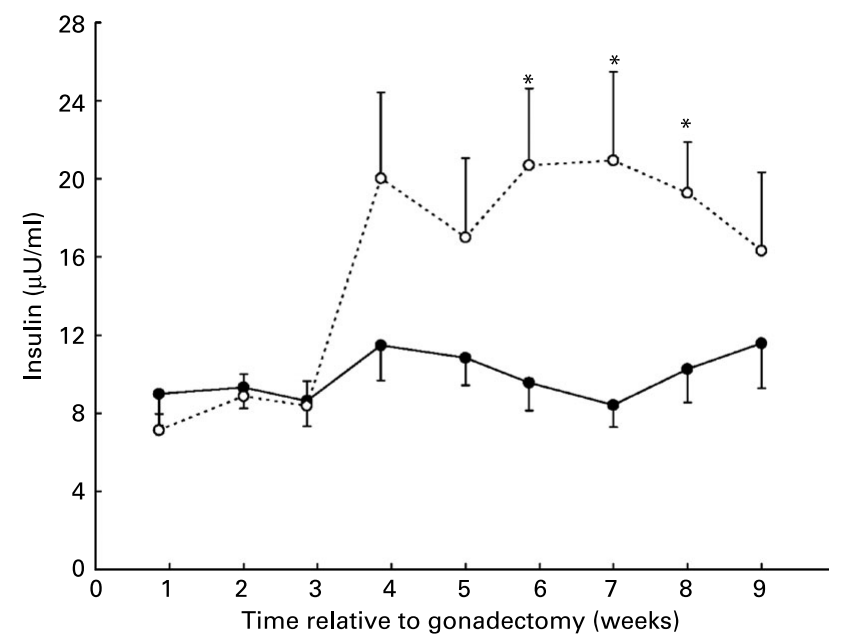

Fig. 4. Plasma insulin concentrations during 9 weeks following gonadectomy of eleven male $(\bullet)$ and twelve female $(\bigcirc)$ cats given purified diets of varying metabolisable energy as fat (9 to $64 \%$ ). Values are means (observations for two to three cats), with their standard errors represented by vertical bars. *Mean value was significantly different from that for females $(P<0.05)$. greatest body weights during the pre-GX period, dietary group differences found in plasma insulin concentration were probably the consequence of adiposity differences. Hence, the results of the present study appear consistent with reports in which plasma insulin concentration in cats is found to rise with increasing body weight.

The feeding of high-carbohydrate diets is suggested to increase the risk for development of diabetes mellitus in otherwise healthy cats ${ }^{5,44}$. In considering this, it is worthwhile to note that the amount of carbohydrate in the diets studied were widely different. Yet, plasma insulin and glucose concentrations did not vary significantly with diet, unless the diet consumed resulted in body-weight gain. Undesired gain in body weight would appear to more importantly impact need for insulin than dietary carbohydrate content.

Plasma ghrelin concentrations were determined in the present study because of emerging evidence of roles for ghrelin in the control of food intake and regulation of body fat mass $^{45}$. During the post-GX period, when food intake increased in all dietary groups, plasma ghrelin concentrations were inversely correlated with dietary fat concentration (Fig. 5). Rodent and human studies report similar findings when diets of varying fat content are given in amounts that induce body-weight gain ${ }^{46,47}$. Our finding of decreasing plasma ghrelin concentration with increasing dietary fat and body weight seems consistent with the orexigenic function suggested for ghrelin. Our finding of greater plasma ghrelin concentration in females than males (Table 6) is similar to sex-difference observations in human subjects ${ }^{48}$. The cause for a sex difference in plasma ghrelin is unknown, but may be related to gonadal function. Ghrelin-gonadal interactions have been identified in other species ${ }^{49}$.

In conclusion, the present study shows that high concentrations of dietary carbohydrate, relative to high fat, do not induce body-weight gain or elevation of plasma glucose and insulin concentrations in sexually intact cats when food is made continuously accessible. Sexually intact cats appear to respond as a species to high concentrations of dietary fat with undesired body-weight gain. A threshold level of dietary fat may be required to induce body-weight gain in sexually intact cats. Gonadectomy stimulates food intake to the degree that undesired gains in body weight and fat follow. Gonadectomy reveals a sex-specific difference in bodyweight gain and eliminates a sex difference in plasma ghrelin concentration. Substitution of dietary carbohydrate with fat 
Table 7. Plasma insulin, glucose and triacylglycerol concentrations in eleven male and twelve female cats given diets for ad libitum consumption before and after gonadectomy (GX)

(Mean values with their standard errors)

\begin{tabular}{|c|c|c|c|c|c|c|}
\hline \multirow[b]{2}{*}{ Period } & \multicolumn{2}{|c|}{ Glucose (mM) } & \multicolumn{2}{|c|}{ TAG (mM) } & \multicolumn{2}{|c|}{ Leptin (ng/ml) } \\
\hline & Mean & SEM & Mean & SEM & Mean & SEM \\
\hline Pre-GX* & $4 \cdot 1$ & 0.2 & 0.9 & 0.1 & $2 \cdot 7$ & 0.3 \\
\hline Post-GX† & 4.0 & 0.0 & 0.7 & 0.1 & $2 \cdot 5$ & 0.2 \\
\hline
\end{tabular}

* Mean of concentrations across diet and sex 2 weeks before GX.

† Mean of concentrations across diet and sex observed during 9 weeks after GX.

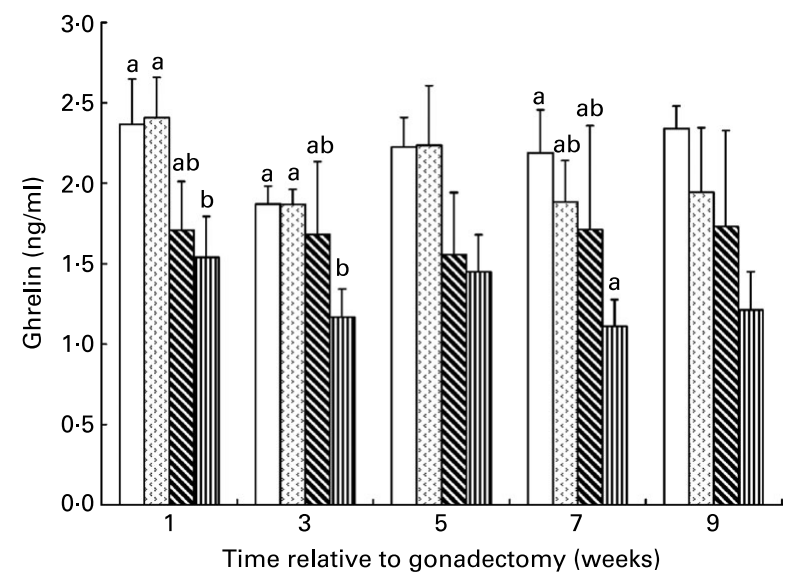

Fig. 5. Plasma ghrelin concentrations observed during weeks 1, 3, 5, 7 and 9 following gonadectomy of eleven male and twelve female cats given purified diets of varying metabolisable energy as fat: $9 \%(\square) ; 25 \%$ (回); $44 \%(\mathbf{\nabla})$; $64 \%$ (四). Values are means (observations for five to six cats), with their standard errors represented by vertical bars. ${ }^{a, b}$ Mean values for a week with unlike letters were significantly different $(P<0.05)$

does not appear to prevent weight gain induced by GX, but it appears to lessen the initial expansion of body fat mass. Overall, the study findings indicate that weight gain induced by high dietary fat and GX are probably more important to consider in the long-term health of cats than dietary carbohydrate content.

\section{Acknowledgements}

The authors gratefully acknowledge provision of funding for the research through a fellowship awarded to N. J. C. by the Center for Companion Animal Heath, School of Veterinary Medicine, University of California, Davis. The authors thank Ms Debbie Bee, Ms Christine Rieger and staff of the Feline Nutrition and Pet Care Center of the School of Veterinary Medicine for their roles in completing the research.

\section{References}

1. MacDonald ML, Rogers QR \& Morris JG (1984) Nutrition of the domestic cat, a mammalian carnivore. Annu Rev Nutr 4, $521-562$.
2. Scarlett JM, Donoghue S, Saidla J \& Wills J (1994) Overweight cats: prevalence and risk factors. Int J Obes Relat Metab Disord 18, S22-S28.

3. West DB, Boozer CN, Moody DL \& Atkinson RL (1992) Dietary obesity in nine inbred mouse strains. Am J Physiol 262, R1025-R1032.

4. Oscai LB, Brown MM \& Miller WC (1984) Effect of dietary fat on food intake, growth and body composition in rats. Growth 48, 415-424.

5. Zoran DL (2002) The carnivore connection to nutrition in cats. $J$ Am Vet Med Assoc 221, 1559-1567.

6. Richard MJ, Holck JT \& Beitz DC (1989) Lipogenesis in liver and adipose tissue of the domestic cat (Felis domestica). Comp Biochem Physiol B 93, 561-564.

7. Nguyen PG, Dumon HJ, Siliart BS, Martin LJ, Sergheraert R \& Biourge VC (2004) Effects of dietary fat and energy on body weight and composition after gonadectomy in cats. Am J Vet Res 65, 1708-1713.

8. Kane E, Leung PM, Rogers QR \& Morris JG (1987) Diurnal feeding and drinking patterns of adult cats as affected by changes in the level of fat in the diet. Appetite 9, 89-98.

9. Lester T, Czarnecki-Maulden G \& Lewis D (1999) Cats increase fatty acid oxidation when isocalorically fed meatbased diets with increasing fat content. Am J Physiol 277, R878-R886.

10. Pet Food Institute (2003) Statistical data on U.S. cat and dog populations. Washington, DC. http://www.petfoodinstitute.org/ reference_pet_data.cfm (accessed December 2005).

11. Lund EM, Armstrong PJ, Kirk CA \& Klausner JS (2005) Prevalence and risk factors for obesity in adult cats from private US veterinary practices. Intern J Appl Res Vet Med 3, $88-96$.

12. Scarlett JM \& Donoghue S (1998) Associations between body condition and disease in cats. J Am Vet Med Assoc 212, $1725-1731$.

13. Association of American Feed Control Officials (2004) Official Publication of the Association of American Feed Control Officials. Oxford, IN: Association of American Feed Control Officials, Inc.

14. National Research Council, Subcommittee on Cat Nutrition, Committee on Animal Nutrition \& Board of Agriculture (1986) Nutrient Requirements of Cats, revised ed. Washington, DC: National Academy Press.

15. National Research Council, Institute of Laboratory Animal Resources \& Commission on Life Sciences (1996) Guide for the Care and Use of Laboratory Animals. Washington, DC: National Institutes of Health.

16. Wilson GP \& Hayes HM Jr (1983) Ovariohysterectomy in the dog and cat. In Current Techniques in Small Animal Surgery, 2nd ed., pp. 334-338 [MJ Bojrab, SW Crane and SP Arnoczky, editors]. Philadelphia, PA: Lea \& Febiger.

17. Crane SW, Smallwood JE \& Wensing CJG (1983) Orchiectomy of descended and retained testes in the dog and cat and biopsy of the testis. In Current Techniques in Small Animal Surgery, 2nd ed., pp. 369-379 [MJ Bojrab, SW Crane and SP Arnoczky, editors]. Philadelphia, PA: Lea \& Febiger.

18. Backus RC, Havel PJ, Gingerich RL \& Rogers QR (2000) Relationship between serum leptin immunoreactivity and body fat mass as estimated by use of a novel gas-phase Fourier transform infrared spectroscopy deuterium dilution method in cats. Am J Vet Res 61, 796-801.

19. Moise NS \& Spaulding GL (1981) Feline bronchial asthma: pathogenesis, pathophysiology, diagnositics, and therapeutic considerations. Compend Contin Educ Pract Vet 3, 1091-1102.

20. Kienzle E (1994) Blood sugar levels and renal sugar excretion after the intake of high carbohydrate diets in cats. J Nutr 124, $2563 \mathrm{~S}-2567 \mathrm{~S}$. 
21. Delavaud C, Bocquier F, Chilliard Y, Keisler DH, Gertler A \& Kann G (2000) Plasma leptin determination in ruminants: effect of nutritional status and body fatness on plasma leptin concentration assessed by a specific RIA in sheep. J Endocrinol 165, $519-526$

22. Atwater WO \& Bryant AP (1900) The availability and fuel values of food materials. In Storrs Station Report for 1899, pp. 73-123 Storrs, CT: Connecticut Agricultural Experiment Station.

23. Crane SW (1991) Occurrence and management of obesity in companion animals. J Small Anim Pract 32, 275-282.

24. Flynn MF, Hardie EM \& Armstrong PJ (1996) Effect of ovariohysterectomy on maintenance energy requirement in cats. $J \mathrm{Am}$ Vet Med Assoc 209, 1572-1581.

25. Root MV, Johnston SD \& Olson PN (1996) Effect of prepuberal and postpuberal gonadectomy on heat production measured by indirect calorimetry in male and female domestic cats. Am $J$ Vet Res 57, 371-374.

26. Fettman MJ, Stanton CA, Banks LL, Johnson DE, Hamar DW, Hegstad RL \& Johnston S (1998) Effects of weight gain and loss on metabolic rate, glucose tolerance, and serum lipids in domestic cats. Res Vet Sci 64, 11-16.

27. Hoenig M \& Ferguson DC (2002) Effects of neutering on hormonal concentrations and energy requirements in male and female cats. Am J Vet Res 63, 634-639.

28. Kanchuk ML, Backus RC, Calvert CC, Morris JG \& Rogers QR (2003) Weight gain in gonadectomized normal and lipoprotein lipase-deficient male domestic cats results from increased food intake and not decreased energy expenditure. J Nutr 133, 1866-1874.

29. Bray GA \& Popkin BM (1998) Dietary fat intake does affect obesity! Am J Clin Nutr 68, 1157-1173.

30. Kane E, Morris JG \& Rogers QR (1981) Acceptability and digestibility by adult cats of diets made with various sources and levels of fat. J Anim Sci 53, 1516-1523.

31. Tremblay A (2004) Dietary fat and body weight set point. Nutr Rev 62, S75-S77.

32. Fettman MJ, Stanton CA, Banks LL, Hamar DW, Johnson DE, Hegstad RL \& Johnston S (1997) Effects of neutering on bodyweight, metabolic rate and glucose tolerance of domestic cats. Res Vet Sci 62, 131-136.

33. Martin L, Siliart B, Dumon H, Backus R, Biourge V \& Nguyen P (2001) Leptin, body fat content and energy expenditure in intact and gonadectomized adult cats: a preliminary study. J Anim Physiol Anim Nutr (Berl) 85, 195-199.

34. Root MV \& Johnston SD (1995) The effect of early spay-neuter in the development of feline obesity. Vet Forum 12, 38-43.

35. Appleton DJ, Rand JS \& Sunvold GD (2001) Insulin sensitivity decreases with obesity, and lean cats with low insulin sensitivity are at greatest risk of glucose intolerance with weight gain. J Feline Med Surg 3, 211-228.
36. Reaven GM (2005) Compensatory hyperinsulinemia and the development of an atherogenic lipoprotein profile: the price paid to maintain glucose homeostasis in insulin-resistant individuals. Endocrinol Metab Clin North Am 34, 49-62.

37. Wilkins C, Long RC Jr, Waldron M, Ferguson DC \& Hoenig M (2004) Assessment of the influence of fatty acids on indices of insulin sensitivity and myocellular lipid content by use of magnetic resonance spectroscopy in cats. Am J Vet Res $\mathbf{6 5}$, 1090-1099.

38. Appleton DJ, Rand JS \& Sunvold GD (2000) Plasma leptin concentrations in cats: reference range, effect of weight gain and relationship with adiposity as measured by dual energy X-ray absorptiometry. J Feline Med Surg 2, 191-199.

39. Shibata H, Sasaki N, Honjoh T, Ohishi I, Takiguchi M, Ishioka K, Ahmed M, Soliman M, Kimura K \& Saito M (2003) Feline leptin: immunogenic and biological activities of the recombinant protein, and its measurement by ELISA. $J$ Vet $\mathrm{Med} S \mathrm{Si}$ 65, 1207-1211.

40. Flier JS (2004) Obesity wars: molecular progress confronts an expanding epidemic. Cell 116, 337-350.

41. Martin LJ, Siliart B, Dumon HJ \& Nguyen P (2006) Spontaneous hormonal variations in male cats following gonadectomy. J Feline Med Surg 8, 309-314.

42. Schwartz MW, Baskin DG, Kaiyala KJ \& Woods SC (1999) Model for the regulation of energy balance and adiposity by the central nervous system. Am J Clin Nutr 69, 584-596.

43. Appleton DJ, Rand JS \& Sunvold GD (2005) Basal plasma insulin and homeostasis model assessment (HOMA) are indicators of insulin sensitivity in cats. J Feline Med Surg 7, 183-193.

44. Rand JS, Fleeman LM, Farrow HA, Appleton DJ \& Lederer R (2004) Canine and feline diabetes mellitus: nature or nurture? J Nutr 134, 2072S-2080S.

45. Williams DL \& Cummings DE (2005) Regulation of ghrelin in physiologic and pathophysiologic states. $J$ Nutr $\mathbf{1 3 5}$, 1320-1325.

46. Moesgaard SG, Ahren B, Carr RD, Gram DX, Brand CL \& Sundler F (2004) Effects of high-fat feeding and fasting on ghrelin expression in the mouse stomach. Regul Pept 120, 261-267.

47. Robertson MD, Henderson RA, Vist GE \& Rumsey RD (2004) Plasma ghrelin response following a period of acute overfeeding in normal weight men. Int J Obes Relat Metab Disord 28, $727-733$

48. Greenman Y, Golani N, Gilad S, Yaron M, Limor R \& Stern N (2004) Ghrelin secretion is modulated in a nutrient- and genderspecific manner. Clin Endocrinol (Oxf) 60, 382-388.

49. Tena-Sempere M (2005) Ghrelin: novel regulator of gonadal function. J Endocrinol Invest 28, Suppl. 5, 26-29.

50. Williams JM, Morris JG \& Rogers QR (1987) Phenylalanine requirement of kittens and the sparing effect of tyrosine. J Nutr 117, 1102-1107. 